\title{
Efficiency of Stock Exchange Markets in G7 Countries: Bootstrap Causality Approach
}

\author{
Ekrem Erdem, Recep Ulucak \\ Erciyes University, Kayseri, Turkey
}

\begin{abstract}
Market efficiency is based on efficient market hypothesis (EMH). EMH claims that market totally contains the available information. In case of EMH, valid investors who take position will not gain abnormal profits. If the efficiency can not be established, that is, if markets are not efficient, investors will have the opportunity of abnormal profits. This paper investigates the causality relations to determine validity of EMH among G7 (Canada, France, Germany, Italy, Japan, United Kingdom, and United States) countries' stock exchange markets for the period from July 2003 to October 2014. To find out whether the variables cause each other or not provides knowledge about the market efficiency. The implication of this analysis is twofold. One implication is that if the markets are informationally efficient, the possibility of abnormal returns through arbitrage is ruled out and investors can reduce the risk of their investment for the same expected returns, if they establish portfolios that consist of both markets rather than consisting of only one market. Based on this, Hacker-Hatemi-J. bootstrap causality test that is newer and has many advantages contrary to other tests was used. Results showed that EMH is valid among each G7 countries' stock exchange markets. Also portfolio diversification benefits exist among these markets.
\end{abstract}

Keywords: efficient market hypothesis (EMH), informational efficiency, portfolio diversification financial econometrics, bootstrap causality

\section{Introduction}

The efficiency of securities markets has led to increasing the studies in this field with Fama (1970). Following Fama (1970), efficient market hypothesis (EMH) is defined as markets which always fully reflect the available information. Essentially, this condition is named as informational efficiency. However, not only informational efficiency but also functionality efficiency (Samuelson, 1965; Merton, 1992; Dow \& Gorton, 1997), insurance efficiency (Arrow \& Debreu, 1954), pricing efficiency (Samuelson, 1975), distributional efficiency, and operational efficiency (O’Hara, 1995) are required, since the markets can scritly be efficient. But Fama's informational efficiency (1970) has been widely tested as a part of EMH in the literature, since informational efficiency is very important and prerequisite among these (Zou, 2011).

In case of markets which are informationally efficient, market participants or investors can not gain abnormal profits. Because when information arises, the news spread very quickly and is incorporated into the prices of securities without delay. Thus technical analysis which is the study of past stock prices in an attemp to

Ekrem Erdem, Ph.D., professor, Erciyes University, Kayseri, Turkey.

Recep Ulucak, Ph.D., Erciyes University, Kayseri, Turkey.

Correspondence concerning this article should be addressed to Recep Ulucak, Erciyes Universty, Iktisadi ve Idari Bilimler Fakultesi, Iktisat Bolumu, Kayseri, Turkey. 
predict future prices would enable an investor to achieve returns greater than the normal profit (Malkiel, 2003). This condition also means that EMH is associated with the random walk theory which assumes a price series where all subsequent price changes represent random departures from the past prices (Dima \& Milos, 2009). If efficiency can not be established, that is, markets are not efficient, investors will have the chance of getting the abnormal profits.

Fama (1970) classified market efficiency into three categories. First is weak form of efficiency, the second is semi-strong form of efficiency, and the third is strong efficiency. Weak form means that prices of securities instantly and completely reflect all information in the past which implies that investors can not gain abnormal returns by using past information. In this form, current prices contain all price information in the past. Semi-strong form means that prices of securities instantly reflect any new publicly available information. Finally, the strong form of the EMH states that prices of securities reflect all information relevant to the firms' information, including information available only to company insiders. As understood, it contains not only publicly available information, but also information which can be had by company insiders. So this form of EMH is quite extreme.

The problem of market efficiency is more important for financial markets in terms of not only informational efficiency or non-efficiency of the financial markets, but also existence or non-existence of international portfolio diversification benefits among the markets (Hatemi-J., 2007). So, various methods have been used in testing the EMH and obtained different results so far. Common method is to test whether the securities data have random walk. That is, unit root tests are the common method. In this study, bootstrap causality test of Hacker and Hatemi-J. (2006) that is newer and has many advantages which will be mentioned in research method section will be used in addition to unit root tests. To find out whether the variables cause each other or not provides knowledge about the market efficiency. This method also tests the semi-strong form of EMH. Unit root tests are used to test the weak form of EMH. Hacker and Hatemi-J. (2006) tested the EMH for USA by this method and reached the result that EMH was valid. Also Hatemi-J. (2007) tested the EMH for USA and UK by this method and results showed that EMH is valid between USA and UK. Hatemi-J. (2007) has suggested new researches which should be made with this method in order to decide whether this method gives consistent results. Based on this motivation, in this paper, EMH will be tested for G7 countries with this method.

\section{Literature Review}

EMH is a matter of study which has been empirically tested for many regions and countries by using various methods. When considering the methods that are used, generally unit root tests, causality, cointegration, auto regressive conditional heteroskedasticity $(\mathrm{ARCH})$, contagion, integration, comovement, spillover, interdependence, interaction, linkage, and correlation analysis leap to the eye. Since contagion and spillover methods are used instead of causality relation, it is true that causality or ARCH methods should be preferred for testing the EMH. Also instead of integration and comovement methods, cointegration method is more proper. Interaction and linkage methods are not used instead of any other methods. Similarly correlation method does not give any result of causality or cointegration (Dong, Latham, \& Bowers, 2013). Unit root tests are the most common method among these. Unit root method essentially tests the random walk theory. Existence of random walk for stock prices means that price changes are random and unpredictable. If a series has unit root, it follows a random walk and EMH is valid. Since unit root method analyzes only past value of a variable, it is used to 
test the EMH in weak form. Cointegration method tests whether series move together in the long run. Accordingly, if series are cointegrated, EMH is valid. Causality method tests which series previously move than other series. To find out whether the variables cause each other or not provides knowledge about the market efficiency. In this case, there must be no causality relation among the series in order to be market efficiency. The causality relation among the global financial markets tests EMH in semi strong form. However, it is required that weak form of EMH is initially tested, since establishing the semi strong form of EMH is not possible without that weak form is valid (Dong et al., 2013).

Although there are so many papers about EMH, those testing directly EMH for G7 countries are limited number. But in this context, papers relevant to other developed country groups which contain G7 countries can be considered in order to comment EMH. So it is useful that studies made for G7 countries and other developed countries are regarded. Zhu (1998) applied panel unit root test to G7 countries for 1958-1996 period and found evidence of efficient markets. Morley and Pentecost (2000) used cointegration test to G7 for 1982-1994 period and reached the result that series moved together in the long run. Balvers, $\mathrm{Wu}$, and Gilliland (2000) tested EMH by employing panel unit root for 18 developed countries including G7 in the period of 1969-1996 and found that markets were not efficient. Similarly for G7, Nieh and Lee (2001) analyzed the hypothesis using cointegration and they did not find any relation in the long run. Bianchi, Drew, and Polichronis (2005) found that markets were efficient in G7 by using moments method for 1980-2004. Narayan and Smith (2005) investigated unit root in 22 OECD countries' data including G7 for 1991-2003 and they reached the result that EMH is valid. Narayan and Smith (2007) applied unit root test with structural breaks to G7 countries for 1975-2003 and they reached result of market efficiency. P. K. Narayan and S. Narayan (2007) investigated G7 countries in terms of market efficiency with SUR and panel unit root methods for 1975-2003 period and noted that EMH is valid. Narayan and Prasad (2007) empirically studied market efficiency in 17 European countries, including four G7 countries using SUR and panel unit root methods for 1988-2003 and the result they reached was that markets were efficient. Narayan (2008) tested EMH in G7 countries, applying panel unit root with structural breaks for period of 1975-2003; C. C. Lee, J. D. Lee, and C. C. Lee (2010) tested EMH in 32 developed countries, including G7 for period of 1999-2007; and Saramat and Dima (2011) applied unit root test to UK, Japan, and USA for 1995-2010 and they found the evidence of market inefficiency.

\section{Research Methods and Results}

In this paper, the validity of EMH in G7 countries is tested with monthly data for the period from July 2003 to October 2014 by using bootstrap causality of Hacker-Hatemi-J. (2006) in addition to unit root tests. Data which are used in this analysis were compiled from investing.com. The variables represent the stock exchange values as follows: NYSE is New York stock exchange; NIKKEI is Tokyo stock exchange; FTSE is London stock exchange; TSX is Canada stock exchange; DAX is Germany stock exchange; CAC is France stock exchange; and ITALY is Italian stock exchange.

This method reformed by Hacker and Hatemi-J. (2006) gives more efficient results in analysis which has usually less observation by producing proper critical values for the data set with bootstrap technic. In addition, since it is based on Toda and Yamamoto's (1995) MWALD test, that this analysis is not econometrically sensitive for integration order and cointegration relation of series gives more reliable results. So it is not required the cointegration analysis and consisting a vector error correction model (Hacker \& Hatemi-J., 2006). The implication of this analysis is twofold. One implication is that if the markets are informationally efficient, 
the possibility of abnormal returns through arbitrage is ruled out and investors can reduce the risk of their investment for the same expected returns, if they establish portfolios that consist of both markets rather than consisting of only one market (Hatemi-J., 2007).

Integration/stationary and lag order of variables in the model should be determined before the causality method suggested by Hacker and Hatemi-J. (2006). Because additional lag must be added to model which tests causality as much as maximum integration degree of the variables. Dickey and Fuller's ADF test (1992) and KPPS test of Kwiatkowski, Phillips, Schmidt, and Shin (1992) were used for determining unit roots that are integration number of variables. Results are presented in Table 1.

Table 1

Unit Root Test Results in Level

\begin{tabular}{lllll}
\hline & \multicolumn{2}{c}{ ADF } & \multicolumn{2}{c}{ KPSS } \\
\cline { 2 - 5 } & $\begin{array}{l}\text { Constant } \\
(-2.882)^{*}\end{array}$ & $\begin{array}{l}\text { Constant \& trend } \\
(-3.443)^{*}\end{array}$ & $\begin{array}{l}\text { Constant } \\
(0.463)^{*}\end{array}$ & $\begin{array}{l}\text { Constant \& trend } \\
(0.146)^{*}\end{array}$ \\
\hline NYSE & -1.225 & -1.472 & 0.431 & 0.145 \\
NIKKEI & -1.224 & -1.205 & 0.204 & 0.160 \\
FTSE & -1.833 & -2.019 & 0.553 & 0.127 \\
TSX & -2.092 & -2.758 & 0.732 & 0.138 \\
DAX & -1.040 & -1.792 & 0.948 & 0.130 \\
CAC & -1.855 & -1.986 & 0.253 & 0.154 \\
ITALY & -1.849 & -1.885 & 0.839 & 0.171 \\
\hline
\end{tabular}

Notes. Null hypothesis of ADF: The series has a unit root; Null hypothesis of KPSS: The series is stationary; * critical values of $5 \%$.

As understood from Table 1, it is seen that each series has unit root, in other words, there is no stationary for each series in the level. When taken first difference of the series, each becomes stationary. So number of additional lag that must be added to model is one. These results also show that EMH is valid in weak form.

Toda and Yamamoto (1995) suggested Wald test which has Chi-square distribution and independent from integration order and stationary of variables by employing a vector auto regressive (VAR) model which is expanded with the lags of variables for testing causality among series. This test uses expanded $\operatorname{VAR}(p+d)$ pattern in equation one. In this equation, $d$ notation added to lag number represents maximum integration number that provides series' stationary.

$$
x_{t}=v+a_{1} x_{t-1}+\ldots+a_{p} x_{t-p}+\ldots+a_{p+d} x_{p+d}+\varepsilon_{t}
$$

This model can be written as a matrix like in equation 2:

$$
Y=\widehat{D} Z+\widehat{\delta}
$$

Toda and Yamamoto (1995) suggested modified MWALD test which has Chi-square distribution and normally distributed error term to test null hypothesis of no Granger causality. MWALD test process is shown in equation 3 :

$$
\operatorname{MVALD}=(C \widehat{\beta})\left\{C\left[\left(Z^{\prime} Z\right)^{-1} \oplus S_{U}\right] C^{\prime}\right\}^{-1}(C \widehat{\beta})
$$

where $\oplus$ is kronecker product; $C$ is $p \times n[1+n(p+d)]$ matrix; $S_{u}$ is variance covariance matrix of the model in equation 2 ; and $\hat{\beta}$ is column stacking operator in equation 3. Null hypothesis of the model states that there is 
no Granger causality.

$$
\mathrm{H}_{0}: C \beta=0
$$

While Todo and Yamamato's model (1995) employs asymptotic distribution, Hacker and Hatemi-j. (2006) proved that MWALD test statistics tend to reject null hypothesis, when especially error term has ARCH and not normal distribution (Y1ldirım \& Kesikoglu, 2012). In addition, Hacker and Hatemi-J. (2006) claimed that asymptotic distribution can be imperfect in small sample sizes. In this case, they suggested bootstrap technic. So this bootstrap causality test is robust to the existence of ARCH. This property of the test seems to be useful, because it is widely agreed in the literature that the volatility of many economic and financial variables has ARCH effects (Hatemi-J., 2007).

Another caution is determining of lag length in the VAR model in order for causality test to give reliable results. Hence authors used Hatemi-J. information criteria (HJC) (2003) which has relatively more successful results contrary to other information criteria. HJC follows a procedure that is calculated by combining Schwarz information criteria (SIC) and Hannan-Quinn information criteria (HQC) (Hatemi-J., 2003). HJC uses equation 5 to choose lag length,

$$
\mathrm{HJC}=\ln \left(\operatorname{det} \widehat{\Omega}_{j}\right)+k\left(\frac{n^{2} \ln T+2 n^{2} \ln (\ln T)}{2 T}\right) \quad k=0, \cdots, K,
$$

where $\operatorname{det} \widehat{\Omega}_{j}$ is variance covariance matrix; $n$ is dimension of VAR model; $T$ is number of observation; and $K$ is maximum lag order. The lag order that minimises HJC is preferred as the optimal lag order. HJC is robust in existence of ARCH effect and it has good forecasting power according to simulation results in Hatemi-J. (2005). The results of bootstrap causality tests are presented in Table 3.

Table 3

The Results of Test for Causality Using the Bootstrap-Corrected Test

\begin{tabular}{llllll}
\hline The null hypothesis & $\begin{array}{l}\text { The estimated } \\
\text { test value } \\
(W)\end{array}$ & $\begin{array}{l}1 \% \text { bootstrap } \\
\text { critical value }\end{array}$ & $\begin{array}{l}5 \% \text { bootstrap } \\
\text { critical value }\end{array}$ & $\begin{array}{l}10 \% \text { bootstrap } \\
\text { critical value }\end{array}$ & $\begin{array}{l}\text { The validity of } \\
\text { EMH }\end{array}$ \\
\hline NYSE $\neq>$ NIKKEI & 1.001 & 6.824 & 3.946 & 2.748 & YES \\
NIKKEI $\neq>$ NYSE & 1.644 & 6.968 & 3.943 & 2.750 & YES \\
NYSE $\neq>$ FTSE & 5.666 & 9.670 & 6.149 & 4.687 & YES \\
FTSE $\neq>$ NYSE & 0.014 & 9.618 & 6.126 & 4.664 & YES \\
NYSE $\neq>$ TSX & 1.914 & 14.207 & 9.769 & 7.810 & YES \\
TSX $\neq>$ NYSE & 1.155 & 8.753 & 5.135 & 3.661 & YES \\
NYSE $\neq>$ DAX & 1.502 & 6.983 & 3.890 & 2.722 & YES \\
DAX $\neq>$ NYSE & 0.927 & 6.990 & 3.943 & 2.755 & YES \\
NYSE $\neq>$ CAC & 0.002 & 6.839 & 3.883 & 2.746 & YES \\
CAC $\neq>$ NYSE & 2.008 & 6.968 & 3.955 & 2.758 & YES \\
NYSE $\neq>$ ITALY & 3.207 & 6.713 & 3.890 & 2.743 & YES \\
ITALY $\neq>$ NYSE & 0.912 & 7.496 & 4.054 & 2.782 & YES \\
NIKKEI $\neq>$ FTSE & 5.807 & 9.530 & 6.198 & 4.734 & YES \\
FTSE $\neq>$ NIKKEI & 1.442 & 9.735 & 6.264 & 4.787 & YES \\
NIKKEI $\neq>$ TSX & 3.429 & 6.924 & 3.956 & 2.790 & YES \\
TSX $\neq>$ NIKKEI & 2.508 & 6.882 & 3.926 & 2.754 & YES \\
NIKKEI $\neq>$ DAX & 0.392 & 6.969 & 3.933 & 2.760 & YES \\
\hline
\end{tabular}


Table 3 continued

\begin{tabular}{|c|c|c|c|c|c|}
\hline The null hypothesis & $\begin{array}{l}\text { The estimated } \\
\text { test value } \\
\text { (W) }\end{array}$ & $\begin{array}{l}1 \% \text { bootstrap } \\
\text { critical value }\end{array}$ & $\begin{array}{l}5 \% \text { bootstrap } \\
\text { critical value }\end{array}$ & $\begin{array}{l}10 \% \text { bootstrap } \\
\text { critical value }\end{array}$ & $\begin{array}{l}\text { The validity of } \\
\text { EMH }\end{array}$ \\
\hline DAX $\neq>$ NIKKEI & 0.886 & 6.958 & 3.910 & 2.735 & YES \\
\hline NIKKEI $\neq>$ CAC & 0.092 & 6.891 & 3.953 & 2.748 & YES \\
\hline CAC $\not>$ NIKKEI & 1.703 & 6.780 & 3.900 & 2.729 & YES \\
\hline NIKKEI $\neq>$ ITALY & 1.465 & 6.941 & 3.952 & 2.753 & YES \\
\hline ITALY $\neq>$ NIKKEI & 1.881 & 7.578 & 4.249 & 2.958 & YES \\
\hline FTSE $\not>$ TSX & 1.668 & 7.330 & 4.136 & 2.895 & YES \\
\hline TSX $\not>$ FTSE & 0.007 & 6.834 & 3.906 & 2.721 & YES \\
\hline FTSE $\not>$ DAX & 0.191 & 6.913 & 3.934 & 2.743 & YES \\
\hline DAX $\neq>$ FTSE & 2.380 & 6.883 & 3.903 & 2.731 & YES \\
\hline FTSE $\neq>$ CAC & 1.443 & 9.877 & 6.362 & 4.823 & YES \\
\hline $\mathrm{CAC} \not>\mathrm{FTSE}$ & 7.267 & 9.700 & 6.228 & 4.754 & YES \\
\hline FTSE $\neq>$ ITALY & 0.195 & 6.746 & 3.895 & 2.741 & YES \\
\hline ITALY $\neq>$ FTSE & 1.406 & 7.240 & 4.052 & 2.823 & YES \\
\hline $\mathrm{TSX} \neq>\mathrm{DAX}$ & 0.012 & 7.055 & 3.915 & 2.711 & YES \\
\hline DAX $\neq>\mathrm{TSX}$ & 3.873 & 7.378 & 4.058 & 2.801 & YES \\
\hline $\mathrm{TSX} \neq>\mathrm{CAC}$ & 0.181 & 6.808 & 3.888 & 2.707 & YES \\
\hline $\mathrm{CAC} \not>\mathrm{TSX}$ & 3.894 & 6.893 & 3.978 & 2.786 & YES \\
\hline TSX $\neq>$ ITALY & 0.614 & 6.827 & 3.908 & 2.739 & YES \\
\hline ITALY $\neq>$ TSX & 2.955 & 7.505 & 3.982 & 2.770 & YES \\
\hline $\mathrm{DAX} \neq>\mathrm{CAC}$ & 0.606 & 6.881 & 3.910 & 2.726 & YES \\
\hline $\mathrm{CAC} \not>\mathrm{DAX}$ & 3.401 & 6.918 & 3.934 & 2.758 & YES \\
\hline DAX $\neq>$ ITALY & 0.315 & 6.716 & 3.883 & 2.740 & YES \\
\hline ITALY $\nRightarrow>$ DAX & 0.290 & 7.720 & 4.047 & 2.765 & YES \\
\hline CAC $\nRightarrow>$ ITALY & 1.769 & 6.706 & 3.893 & 2.744 & YES \\
\hline ITALY $\nRightarrow>$ CAC & 0.715 & 7.513 & 4.337 & 3.067 & YES \\
\hline
\end{tabular}

Notes. Gauss codes written by Hacker and Hatemi-J. (2006) were used for estimating the causality test results; NYSE $\neq>$ NIKKEI means that there is no Granger causality from New York stock exchange to Tokyo stock exchange.

According to these results on Table 3, null hypothesis of no causality can not be rejected for each paired samples in the confidence interval of $1 \%$ and $5 \%$. But when authors enlarged the confidence interval to $10 \%$, null hypothesis was rejected just for a few paired samples. So, EMH is valid among each G7 countries' stock exchange markets. This result also means that portfolio diversification benefits exist among these markets.

\section{Conclusions}

EMH was tested for many countries by different methods and various results were obtained. The majority of these methods are based on unit root analysis in literature. So these studies tested the weak form of EMH. In this paper, causality analysis was used and EMH was tested in semi strong form in addition to unit root tests. Many papers testing EMH in G7 countries had a result that EMH is valid. In this paper, firstly EMH was tested by unit root tests and result was obtained that the weak form of EMH is valid for each G7 country. Then, it performed the causality test in paired samples (like in Table 3) and also obtained result that EMH is valid in semi strong form. Based on this, it can be said that EMH is valid for G7 countries in weak and semi strong form. So any investor who takes position for G7 stock exchange markets can not gain abnormal profit by using past information and any new publicly available information and also the result can be reached that 
international portfolio benefits exist among G7 stock exchange markets. So, investors can reduce the risk of their investment for the same expected returns, if they establish portfolios that consist of both markets rather than consisting of only one market.

\section{References}

Arrow, K., \& Debreu, G. (1954). Existence of an equilibrium for a competitive economy. Econometrica, 22(3), 265-290.

Balvers, R., Wu, Y., \& Gilliland, E. (2000). Mean reversion across national stock markets and parametric contrarian investment strategies. Journal of Finance, 55, 745-772.

Bianchi, R. J., Drew, M. E., \& Polichronis, J. (2005). A test of momentum trading strategies in foreign exchange markets: Evidence from the G7. Global Business and Economics Review, 7(2/3), 155-179.

Dickey, D., \& Fuller, W. (1981). Likelihood ratio statistics for autoregressive time series with a unit root. Econometrica, 49, 1057-1072.

Dima, B., \& Milos, L. R. (2009). Testing the efficiency market hypothesis for the Romanian stock market. Annales Universitatis Apulensis Series Oeconomica, 11(1), 402-415.

Dong, H., Latham, W., \& Bowers, H. (2013). Evidence on the efficient market hypothesis from 44 global financial market indexes. Economics Research International, 10, 1-11.

Dow, J., \& Gorton, G. (1997). Stock market efficiency and economic efficiency: Is there a connection? Journal of Finance, 52(3), $1087-1129$.

Fama, E. (1970). Efficient capital markets: A review of theory and empirical work. Journal of Finance, 25, 383-417.

Hacker, R. S., \& Hatemi-J., A. (2006). Tests for causality between integrated variables using asymptotic and bootstrap distributions: Theory and application. Applied Economics, 38, 1489-1500.

Hatemi-J., A. (2003). A new method to choose optimal lag order in stable and unstable VAR models. Applied Economics Letters, 10(3), 135-137.

Hatemi-J., A. (2005). Forecasting properties of a new method to determine optimal lag order in stable and unstable VAR models. Applied Economics Letters, 15(4), 239-243.

Hatemi-J., A. (2007). A bootstrap test for causality with endogenous lag length choice: Theory and application in finance. Proceedings from Oxford Business and Economics Conference, Oxford, UK. Retrieved from http://www.gcbe.us/2007_OBEC/data/confcd.htm

Kwiatkowski, D., Phillips, P. C. B., Schmidt, P., \& Shin, Y. (1992). Testing the null hypothesis of stationarity against the alternative of a unit root. Journal of Econometrics, 54, 159-178.

Lee, C. C., Lee, J. D., \& Lee, C. C. (2010). Stock price and the efficient market hypothesis: Evidence from a panel stationary test with structural breaks. Japan and World Economy, 22, 49-58.

Malkiel, B. G. (2003). The efficient market hypothesis and its critics. Journal of Economic Perspectives, 17(1), 59-82.

Merton, R. C. (1992). Continuous-time finance. Malden, Mass.: Blackwell Publishers Inc.

Morley, B., \& Pentecost, E. J. (2000). Common trends and cycles in G-7 countries exchange rates and stock prices. Applied Economic Letters, 7, 7-10.

Narayan, P. K. (2008). Do shocks to G7 stock prices have a permanent effect? Mathematics and Computers in Simulation, 77, 369-373.

Narayan, P. K., \& Narayan, S. (2007). Mean reversion in stock prices: New evidence from panel unit root tests. Studies in Economics and Finance, 24(3), 233-244.

Narayan, P. K., \& Prasad, A. (2007). Mean reversion in stock prices: New evidence from panel unit root tests for seventeen European countries. Economics Bulletin, 3, 1-6.

Narayan, P. K., \& Smyth, R. (2005). Are OECD stock prices characterized by a random walk? Evidence from sequential trend break and panel data models. Applied Financial Economics, 15, 547-556.

Narayan, P. K., \& Smyth, R. (2007). Mean reversion versus random walk in G7 stock prices evidence from multiple trend break unit root tests. Journal of International Financial Markets, Institutions and Money, 17, 152-166.

Nieh, C. C., \& Lee, C. F. (2001). Dynamic relationship between stock prices and exchange rates for G-7 countries. The Quarterly Review of Economics and Finance, 41, 477-490.

O'Hara, M. (1995). Market microstructure theory. Oxford: Basil Blackwell Publisher.

Samuelson, P. (1965). Proof that properly anticipated prices fluctuate randomly. Industrial Management Review, 6(2), 41-49. 
Samuelson, P. (1975). Optimum social security in a life-cycle growth model. International Economic Review, 16(3), 539-544.

Saramat, O., \& Dima, B. (2011). Testing the weak form informational efficiency of United Kingdom, United States of America and Japan's capital market. Timisoara Journal of Economics, 2(14), 111-122.

Toda, H. Y., \& Yamamoto, T. (1995). Statistical inference in vector autoregressions with possibly integrated processes. Journal of Econometrics, 66, 225-250.

Yıldırım, E., \& Kesikoglu, F. (2012). İthalat-ihracat-döviz kuru bağımlılı̆̆ı: Bootstrap ile düzeltilmiş nedensellik testi uygulaması. Ege Akademik Bakış, 12(2), 137-148.

Zhu, Z. (1998). The random walk of stock prices: Evidence from a panel of G7 countries. Applied Economics Letters, 5, 411-413.

Zou, H. (2011). Information efficiency of stock markets. International Journal of Innovative Management, Information \& Production, 2(3), 40-48. 